\title{
QUALIDADE FISIOLÓGICA DE SEMENTES DE TRIGO EM RESPOSTA AOS EFEITOS DE ANOS E ÉPOCAS DE SEMEADURA ${ }^{1}$
}

\author{
JOSELAINE VIGANÓ², ALESSANDRO DE L. E BRACCINI ${ }^{3}$, CARLOS A. SCAPIM ${ }^{3}$, \\ FRANCISCO DE A. FRANCO ${ }^{4}$, IVAN SCHUSTER ${ }^{4}$, LIA M. MOTERLE ${ }^{5}$, LEANDRA R. TEXEIRA ${ }^{6}$
}

\begin{abstract}
RESUMO - O trabalho foi realizado com o objetivo de avaliar a qualidade fisiológica de sementes de cultivares de trigo em resposta aos efeitos de anos e épocas de semeadura. Para tanto, nos anos de 2006 e 2007, sementes de trigo das cultivares CD 104, CD 105, CD 108, CD 110, CD 111 e CD 114 foram semeadas em 22/03, 07 e 20/04, 04 e 18/05, na região de Palotina, PR. Foram analisados as seguintes características: germinação, classificação do vigor das plântulas e envelhecimento acelerado. Os dados foram submetidos à análise de variância conjunta entre os dois anos de experimento e realizaramse os desdobramentos entre cultivares, épocas de semeadura e anos, em todas as combinações. Em relação à germinação, verificou-se que as cultivares CD 105 e CD 108 foram menos influenciadas pelas épocas de semeadura nos dois anos de cultivo. Observou-se ainda, que as épocas 22/03, 07/04 e 18/05, em 2006, não foram ideais para as cultivares CD 110, CD 111 e CD 114, avaliadas pelos testes de germinação, classificação de vigor das plântulas e envelhecimento acelerado. Conclui-se que, para a maioria das épocas de semeadura e cultivares, em 2007, foram obtidas maiores porcentagens de plântulas normais do que em 2006. Constatou-se ainda que, a maioria das cultivares apresentou maior similaridade entre os anos, na época de semeadura de 20/04 em relação aos testes de germinação e classificação do vigor das plântulas.
\end{abstract}

Termos para indexação: Triticum aestivum, potencial fisiológico, germinação, vigor.

\section{PHYSIOLOGICAL QUALITY OF WHEAT SEEDS IN RESPONSE TO YEARS AND SOWING DATES}

\begin{abstract}
The objective of this study was to evaluate the physiological quality of wheat seeds in response to the effects of years and sowing dates. In 2006 and 2007 seeds of the wheat cultivars CD 104, CD 105, CD 108, CD 110, CD 111 and CD 114 were sown on March 22 $2^{\text {nd }}$, April $7^{\text {th }}$ and $20^{\text {th }}$, May $4^{\text {th }}$ and $18^{\text {th }}$, in the Palotina region, Paraná State. It was analysed the following traits: germination, seedling vigor classification and accelerated ageing. The data were subjected to joint variance analysis between the two years of the experiment and cultivars, sowing dates and years, for all combinations. The germination of the cultivars CD 105 and CD 108 were less influenced by sowing dates in both crop years. The results from germination tests, classification of seedling vigor and accelerated ageing showed that the sowing periods of March $22^{\text {nd }}$, April $7^{\text {th }}$ and May $18^{\text {th }}$, in 2006 ,
\end{abstract}

\begin{abstract}
${ }^{1}$ Submetido em 05/10/2009. Aceito para publicação em 20/04/2010. Parte da Dissertação de Mestrado do Primeiro autor apresentada a Universidade Estadual de Maringá - UEM.
\end{abstract}

${ }^{2}$ Bióloga, M.Sc., Pós-graduanda em Genética e Melhoramento, UEM, Av. Colombo, 5.790, Cep: 87020-900 Maringá-PR. E-mail: josyvigano@ hotmail.com.

${ }^{3}$ Eng. Agr., D.S. Professor Associado do Departamento de Agronomia, UEM, Av. Colombo, 5790, CEP 87020-900, Maringá, PR, E-mail: albraccini@uol.com.br; cascapim@uem.br.
${ }^{4}$ Eng. Agr., D.S., Pesquisador da Cooperativa Central de Pesquisa Agrícola, Cx. Postal 301, Cascavel, PR, CEP 85813-450, E-mail: franco@coodetec.com.br; ivan@coodetec.com.br.

${ }^{5}$ Eng. Agr., M.Sc., Pós-graduanda em Agronomia, UEM, Av. Colombo, 5790, Cep: 87020-900, Maringá-PR. E-mail: 1moterle@hotmail.com

${ }^{6}$ Bióloga, D.S., Bolsista de Pós-doutorado Empresarial na Cooperativa Central de Pesquisa Agrícola, Caixa Postal 301, CEP 85813-450, Cascavel, PR. E-mail: leandrart@hotmail.com 
were not ideal for cultivars CD 110, CD 111 and CD 114. Most sowing dates and cultivars in 2007 showed higher percentages of normal seedlings than for 2006. Furthermore, most of the cultivars showed greater similarity between the years for the April $20^{\text {th }}$ sowing date according to the results of the tests for germination and classification of seedling vigor.

Index terms: Triticum aestivum, physiological potential, germination, vigor.

\section{INTRODUÇÃO}

A utilização de sementes de elevada qualidade fisiológica aliada a práticas culturais adequadas, favorecem a obtenção de estandes mais uniformes e incremento no rendimento de grãos (Lima et al., 2006). No entanto, as condições climáticas também interferem no ciclo das culturas. Assim, a escolha da época de semeadura é um dos fatores cruciais para a qualidade das sementes. A adequação das épocas de semeadura, na cultura do trigo, tem a finalidade de reduzir ao mínimo, possíveis riscos, tais como geadas, déficits hídricos no subperíodo do espigamento e excesso de chuvas na colheita (IAPAR, 2002). Precipitações pluviais leves no início do cultivo facilitam a germinação, o perfilhamento, o emborrachamento e a floração (Lomas, 1976; Mota, 1989). No entanto, na maturação, chuvas frequentes, com temperaturas entre 20 e $25^{\circ} \mathrm{C}$ e alta umidade relativa do ar, aumentam a incidência de doenças, sendo comum a germinação do grão ainda na espiga, o que altera sua qualidade (Silva, 1971; Godoy e Bernardes, 1989; Linhares e Nedel, 1989; Manfron et al., 1993).

O potencial fisiológico das sementes, rotineiramente é avaliado por meio do teste de germinação (Brasil, 1992), o qual analisa a capacidade das sementes produzirem plântulas normais, em condições ideais de temperatura, umidade e substrato (Lima et al., 2006). Porém, nem sempre tal teste revela diferenças de desempenho entre os genótipos, sob condições adversas, após a semeadura ou durante o armazenamento. No campo, principalmente quando ocorre estresse hídrico e térmico, as respostas apresentadas pelas sementes podem ser bem variadas (Maia et al., 2007). Assim, supõe-se que, os testes de vigor permitam distinguir, com maior segurança, lotes ou genótipos de elevado e baixo vigor, fornecendo informações adicionais ao teste de germinação. Contudo, é pouco provável que, um único teste de vigor, possa ser apropriado, mesmo para uma única espécie sob todas as condições (Hampton e Coolbear, 1990). Portanto, sugere-se a utilização conjunta dos resultados de vários testes para a avaliação do vigor de sementes (Egli e
TeKrony, 1979).

Dada à importância da determinação de épocas de semeadura, baseada nas condições edafoclimáticas de cada região, e sua interferência na qualidade de sementes, a literatura apresenta alguns trabalhos abordando esta interação. Sá et al. (1997) avaliaram diferentes épocas de semeadura em arroz irrigado e identificaram que a época mais tardia apresentou uma boa opção para a produção de sementes. De acordo com Pereira et al. (2000) e Braccini et al. (2003), sementes de soja produzidas no período não indicado para a cultura, apresentaram potencial fisiológico inferior aos observados quando o plantio foi realizado na época preferencial. Coimbra e Nakagawa (2006) e Toledo et al. (2009), obtiveram por meio de testes de vigor, resultados interessantes quanto à determinação da época mais promissora para a produção de sementes de milheto. Por outro lado, Albrecht et al. (2008), constataram que a antecipação na semeadura e a época preferencial não são propícios à obtenção de sementes de soja com melhor desempenho fisiológico. Em relação à cultura do trigo, tem sido realizados diversos trabalhos visando à determinação da qualidade fisiológica de sementes, a exemplo de Garcia et al. (2005), Fanan et al. (2006), Lima et al. (2006), Smanhotto et al. (2006) e Soltani et al. (2009). No entanto, são escassas as pesquisas que associem épocas de semeadura e qualidade fisiológica. Assim, objetivouse no presente trabalho avaliar o potencial fisiológico de sementes de cultivares de trigo em resposta aos efeitos de anos e épocas de semeadura.

\section{MATERIAL E MÉTODOS}

O experimento de campo foi conduzido na Fazenda Experimental da Cooperativa Central de Pesquisa Agrícola (Coodetec), em Palotina, localizada na região oeste do Estado do Paraná. Os ensaios consistiram de seis cultivares de trigo (CD 104, CD 105, CD 108, CD 110, CD 111 e CD 114), semeadas em cinco épocas de semeadura nas datas 22 de março, 07 e 20 de abril, 04 e 18 de maio, nos anos de 2006 e 2007. O delineamento experimental foi em 
blocos completos, com tratamentos ao acaso e quatro repetições. Cada parcela consistiu de 6 linhas de 5,0 metros de comprimento, espaçadas de $0,20 \mathrm{~m}$ entre linhas, tendo uma área útil de $6 \mathrm{~m}^{2}$. A densidade utilizada foi de 350 sementes por metro quadrado. Para proporcionar boas condições de crescimento e desenvolvimento das plantas, foi realizada, quando necessário, adubação de cobertura, controle fitossanitário e capina, de acordo com as recomendações técnicas para a cultura do trigo. $\mathrm{Na}$ maturação, caracterizada quando os nós das plantas murcharam, realizou-se a colheita mecânica das parcelas dos diferentes ensaios. As sementes foram armazenadas durante cerca de um mês, no Laboratório Genético de Trigo da Coodetec, em Cascavel, Estado do Paraná, a temperatura ambiente. Em seguida, no Laboratório de Tecnologia de Sementes do Núcleo de Pesquisa Aplicada à Agricultura (NUPAGRI) da Universidade Estadual de Maringá (UEM), foram conduzidos os seguintes testes:

Teste de germinação - foram utilizadas quatro subamostras de 50 sementes para cada tratamento e repetição, colocadas para germinar entre três folhas de papel-toalha, umedecidas com água destilada na proporção de três vezes a massa seca do substrato. Os rolos confeccionados foram levados ao germinador regulado à temperatura constante de $20 \pm 2{ }^{\circ} \mathrm{C}$. As avaliações foram realizadas aos quatro e oito dias após a semeadura e os resultados expressos em porcentagem de plântulas normais (Brasil, 1992).

Classificação do vigor das plântulas - conduzido em conjunto com o teste padrão de germinação, utilizandose quatro subamostras de 50 sementes (Brasil, 1992). Na contagem final de germinação (oito dias após a semeadura), computou-se a porcentagem de plântulas normais fortes (Nakagawa, 1999).

Envelhecimento acelerado - realizado com quatro subamostras de 50 sementes para cada tratamento e repetição, distribuídas sobre uma tela metálica fixada no interior de caixas plásticas tipo "gerbox", de modo a formar uma camada simples. Anteriormente a este procedimento, adicionaram-se $40 \mathrm{~mL}$ de água ao fundo de cada caixa. Estas foram tampadas, obtendo-se, assim, cerca de $100 \%$ de UR em seu interior e foram então mantidas a $43{ }^{\circ} \mathrm{C}$ durante 48 horas em estufa incubadora do tipo B.O.D. Tal metodologia foi escolhida devido ao resultado satisfatório obtido por Lima et al. (2006). Posteriormente ao período de envelhecimento, as sementes foram submetidas ao teste de germinação, conforme metodologia descrita por Brasil (1992). A avaliação foi realizada aos quatro dias após a semeadura e os resultados expressos em porcentagem de plântulas normais. Determinou-se o grau de umidade das sementes antes e após o envelhecimento, pelo método da estufa a $105^{\circ} \mathrm{C}$ por 24 horas (Brasil, 1992).

Os dados foram submetidos à análise de variância individual das épocas para os dois anos. Procedeu-se também à análise de variância conjunta para as cultivares, épocas de semeadura e anos, a partir do modelo fatorial proposto por Cruz et al. (2004), uma vez que a razão entre o maior e o menor quadrado médio residual não foi superior a 7 (Banzatto e Kronka, 1989). As médias das cultivares, em cada combinação de épocas de semeadura e anos e as médias de épocas de semeadura, em cada combinação de cultivares e anos foram comparadas pelo teste de agrupamento de Scott-Knott $(1974)(p<0,05)$. Com relação às comparações de anos, em cada combinação de cultivares e épocas de semeadura, utilizou-se o teste $\mathrm{F}$, a $5 \%$ de probabilidade que foi conclusivo. Utilizou-se o programa estatístico Sisvar (Ferreira, 1999).

\section{RESULTADOS E DISCUSSÃO}

Os dados climatológicos referentes aos períodos de condução dos experimentos, nos dois anos, foram coletados diariamente pela Estação Metereológica do IAPAR em Palotina. Observou-se que a umidade relativa do ar (U.R.) apresentou-se oscilante, nos dois anos. Em 2006, a mínima registrada foi de $63,44 \%$ e a máxima de $83,74 \%$; em 2007 , a U.R. mínima foi de $49,90 \%$ e a máxima de $84,99 \%$. A temperatura média do ar oscilou entre 25,18 e $25,46{ }^{\circ} \mathrm{C}$, com temperatura máxima de $33,74{ }^{\circ} \mathrm{C}$ (março) e mínima de $6,62{ }^{\circ} \mathrm{C}$ (maio), em 2006, enquanto que, no ano de 2007, a temperatura máxima registrada foi de $34,42{ }^{\circ} \mathrm{C}$ (março) e a mínima de $4,99{ }^{\circ} \mathrm{C}$ (julho), no ano de 2007. De acordo com Scheeren et al. (2000), o efeito de baixas temperaturas na cultura de trigo produz resultados diferenciados, dependendo do estádio de desenvolvimento em que ocorre.

Em relação à precipitação pluvial, de maneira geral, pôdese verificar que, nas semeaduras realizadas entre os meses de março e abril (2006), houve precipitação de 150 e 99,2 $\mathrm{mm}$, respectivamente. Na maturação (agosto e setembro), ocorreram períodos com elevada precipitação pluvial, dificultando assim, o processo de colheita das sementes. Nessa fase do experimento conduzido em Palotina, PR, observou-se que em agosto, a precipitação foi de $86,4 \mathrm{~mm}$; em setembro, foi registrada a maior precipitação durante a condução dos ensaios, atingindo-se $209 \mathrm{~mm}$. Esses períodos correspondem a colheita da maioria dos genótipos avaliados. 
Por outro lado, no ano de 2007, ocorreram maiores períodos chuvosos nas fases iniciais do desenvolvimento das plântulas, enquanto que durante o processo de maturação, a precipitação registrada foi mínima, permitindo a colheita dos materiais, em geral, no momento adequado. Do ponto de vista fisiológico, tal evento pode ter propiciado às sementes, os principais elementos indispensáveis no processo de germinação, especialmente, a temperatura, luz e nutrientes (Castro et al., 2004). Este fator pode ter potencializado o número de sementes viáveis, que contribuiu para expressar maior quantidade de plântulas para as diferentes cultivares.

As sementes requerem determinadas condições para germinarem (Castro et al., 2004). Sabe-se que a germinabilidade e o vigor das sementes são condicionados por características genéticas (Mós, 2003), influenciados por sinais externos (ambientais), que quando percebidos pela semente desencadeiam sinais internamente, em nível molecular, os quais induzem a ativação dos processos metabólicos, culminando com o crescimento do eixo embrionário (Carvalho e Nakagawa, 2000; Castro et al., 2004). No presente trabalho, verificou-se que em 2006, a época de semeadura 20/04, permitiu que todas as cultivares apresentassem porcentagem de germinação significativamente superior a $87 \%$ (Tabela 1). Em 2007, em todas as épocas de semeadura, todas as cultivares apresentaram germinação acima de $82 \%$. Portanto, tais resultados estão de acordo com a Instrução Normativa $\mathrm{n}^{\circ} 25$, de 16 de Dezembro de 2005, a qual estabelece germinação mínima aceitável para o trigo de $80 \%$, para produção de sementes de primeira e segunda geração (MAPA, 2009).

TABELA 1. Resultados médios para os desdobramentos das interações entre cultivares, anos e épocas referentes à germinação (\%) das sementes de seis cultivares de trigo, em resposta a cinco épocas de semeadura em experimentos conduzidos no município de Palotina - PR, nos anos 2006 e 2007.

\begin{tabular}{ccccccc}
\hline \multirow{2}{*}{$\begin{array}{c}\text { Épocas de } \\
\text { semeadura }\end{array}$} & \multicolumn{5}{c}{ Cultivares } \\
\cline { 2 - 7 } Ano 2006 & CD 104 & CD 105 & CD 108 & CD 110 & CD 111 & CD 114 \\
\hline $22 / 03$ & $91,75 \mathrm{aA}^{*}$ & $86,50 \mathrm{aA}$ & $93,00 \mathrm{aA}$ & $69,25 \mathrm{bB}$ & $76,25 \mathrm{bB}$ & $67,00 \mathrm{bC}$ \\
$07 / 04$ & $85,00 \mathrm{aA}$ & $69,00 \mathrm{bB}$ & $87,00 \mathrm{aA}$ & $48,50 \mathrm{cC}$ & $50,25 \mathrm{cD}$ & $55,50 \mathrm{cD}$ \\
$20 / 04$ & $87,00 \mathrm{aA}$ & $93,75 \mathrm{aA}$ & $91,75 \mathrm{aA}$ & $86,00 \mathrm{aA}$ & $92,75 \mathrm{aA}$ & $95,25 \mathrm{aA}$ \\
$04 / 05$ & $66,75 \mathrm{bB}$ & $90,50 \mathrm{aA}$ & $92,75 \mathrm{aA}$ & $84,25 \mathrm{aA}$ & $92,25 \mathrm{aA}$ & $86,25 \mathrm{aB}$ \\
$18 / 05$ & $70,25 \mathrm{bB}$ & $75,00 \mathrm{aB}$ & $76,75 \mathrm{aB}$ & $50,00 \mathrm{cC}$ & $64,00 \mathrm{bC}$ & $75,50 \mathrm{aC}$ \\
\hline Ano 2007 & CD 104 & CD 105 & CD 108 & $\mathrm{CD} 110$ & CD 111 & $\mathrm{CD} 114$ \\
\hline $22 / 03$ & $95,00 \mathrm{aA}$ & $95,50 \mathrm{aA}$ & $92,00 \mathrm{aA}$ & $92,75 \mathrm{aA}$ & $96,75 \mathrm{aA}$ & $88,25 \mathrm{aB}$ \\
$07 / 04$ & $94,00 \mathrm{aA}$ & $96,50 \mathrm{aA}$ & $97,75 \mathrm{aA}$ & $96,25 \mathrm{aA}$ & $97,25 \mathrm{aA}$ & $86,25 \mathrm{bB}$ \\
$20 / 04$ & $83,50 \mathrm{bB}$ & $95,00 \mathrm{aA}$ & $93,50 \mathrm{aA}$ & $82,50 \mathrm{bB}$ & $86,25 \mathrm{bB}$ & $82,50 \mathrm{bB}$ \\
$04 / 05$ & $91,00 \mathrm{aA}$ & $94,75 \mathrm{aA}$ & $98,00 \mathrm{aA}$ & $96,00 \mathrm{aA}$ & $98,25 \mathrm{aA}$ & $96,75 \mathrm{aA}$ \\
$18 / 05$ & $98,00 \mathrm{aA}$ & $96,75 \mathrm{aA}$ & $95,50 \mathrm{aA}$ & $92,00 \mathrm{aA}$ & $97,75 \mathrm{aA}$ & $96,75 \mathrm{aA}$ \\
\hline
\end{tabular}

*Médias seguidas de pelo menos uma mesma letra, minúscula na linha, e maiúscula na coluna, pertencem ao mesmo agrupamento de acordo com ScottKnott (1974), em nível de 5\% de significância.

No estudo comparativo dentro das épocas de semeadura (Tabela 1), observou-se no ano de 2006, que a cultivar CD 104 apresentou melhor período para a produção de sementes de março a abril. Em 2007, para esta cultivar, todas as épocas foram consideradas ideais para a semeadura, exceto 20/04. Deve-se ressaltar que, independente da época de semeadura empregada, no ano de 2007 , as cultivares CD 105 e CD 108 apresentaram germinação das sementes superior a $92 \%$. A partir disso, é possível admitir que tais cultivares podem ser semeadas em todas as datas de plantio, resultando em elevadas porcentagens de germinação; isto significa que estas cultivares são ideais para a produção de sementes (MAPA, 2009).

Verificou-se, ainda, que as épocas antecipadas de 22/03 e 07/04 não permitiram as cultivares CD 110, CD 111 e CD 114, a obtenção de elevados índices de germinação nas sementes, em 2006. As cultivares citadas anteriormente são de ciclo precoce/médio e, como no mês de agosto ocorreram precipitações próximas ou no período da colheita, estas podem ter influenciado na qualidade das sementes de forma 
similar para as três cultivares. Do mesmo modo, a época de semeadura mais tardia (18/05) também afetou negativamente a germinação de todas as cultivares avaliadas. Estes resultados estão de acordo com os encontrados por Motta et al. (2002) e Silva et al. (2007), os quais observaram que, tanto a antecipação quanto o atraso na época de semeadura, foram prejudiciais para a obtenção de sementes de soja com qualidade fisiológica superior.

Para as cultivares CD 104 e CD 108, quando a semeadura foi realizada em 22/03, não houve diferença significativa $(\mathrm{p}>0,05)$ entre os anos. No entanto, para as demais cultivares, diferenças significativas foram detectadas e as porcentagens de plântulas normais de 2007 superaram as de 2006. Pode-se observar claramente que em 2007, para todas as cultivares, independente da época em que foram semeadas, as porcentagens de germinação das sementes foram maiores que $82 \%$ (Tabela 2). Uma das prováveis explicações para as diferenças encontradas entre os anos pode ser devido às variações climáticas, principalmente, em relação às precipitações pluviais elevadas na ocasião da colheita, ocorridas no ano de 2006. Resultados discrepantes entre anos também foram encontrados por Braccini et al. (2003) e Albrecht et al. (2008).

TABELA 2. Resultados médios para o desdobramento da interação anos, cultivares e épocas para a característica germinação (\%) das sementes de seis cultivares de trigo, em resposta a cinco épocas de semeadura em experimentos conduzidos no município de Palotina - PR, nos anos 2006 e 2007.

\begin{tabular}{|c|c|c|c|c|c|c|}
\hline \multirow{4}{*}{ Anos } & \multicolumn{6}{|c|}{ Germinação (\%) } \\
\hline & \multicolumn{6}{|c|}{ Cultivares } \\
\hline & CD 104 & CD 105 & CD 108 & CD 110 & CD 111 & CD 114 \\
\hline & \multicolumn{6}{|c|}{ Épocas de Semeadura $(22 / 03)$} \\
\hline 2006 & $91,75 \mathrm{a}^{*}$ & $86,50 \mathrm{~b}$ & $93,00 \mathrm{a}$ & $69,25 \mathrm{~b}$ & $76,25 \mathrm{~b}$ & $67,00 \mathrm{~b}$ \\
\hline 2007 & $95,00 \mathrm{a}$ & $95,50 \mathrm{a}$ & $92,00 \mathrm{a}$ & $92,75 \mathrm{a}$ & $96,75 \mathrm{a}$ & $88,25 \mathrm{a}$ \\
\hline \multicolumn{7}{|c|}{ Épocas de Semeadura (07/04) } \\
\hline 2006 & $85,00 \mathrm{~b}$ & $69,00 \mathrm{~b}$ & $87,00 \mathrm{~b}$ & $48,50 \mathrm{~b}$ & $50,25 \mathrm{~b}$ & $55,50 \mathrm{~b}$ \\
\hline 2007 & $94,00 \mathrm{a}$ & $96,50 \mathrm{a}$ & $97,75 \mathrm{a}$ & $96,25 \mathrm{a}$ & $97,25 \mathrm{a}$ & $86,50 \mathrm{a}$ \\
\hline \multicolumn{7}{|c|}{ Épocas de Semeadura (20/04) } \\
\hline 2006 & $87,00 \mathrm{a}$ & $93,75 \mathrm{a}$ & $91,75 \mathrm{a}$ & $86,00 \mathrm{a}$ & 92,75 a & $95,25 \mathrm{a}$ \\
\hline 2007 & $83,50 \mathrm{a}$ & $95,00 \mathrm{a}$ & $93,50 \mathrm{a}$ & $82,50 \mathrm{a}$ & $86,25 \mathrm{a}$ & $82,50 \mathrm{~b}$ \\
\hline \multicolumn{7}{|c|}{ Épocas de Semeadura $(04 / 05)$} \\
\hline 2006 & $66,75 \mathrm{~b}$ & $90,50 \mathrm{a}$ & $92,75 \mathrm{a}$ & $84,25 \mathrm{~b}$ & $92,25 \mathrm{a}$ & $86,25 \mathrm{~b}$ \\
\hline 2007 & $91,00 \mathrm{a}$ & $94,75 \mathrm{a}$ & $98,00 \mathrm{a}$ & $96,00 \mathrm{a}$ & $98,25 \mathrm{a}$ & $96,75 \mathrm{a}$ \\
\hline \multicolumn{7}{|c|}{ Épocas de Semeadura $(18 / 05)$} \\
\hline 2006 & $70,25 \mathrm{~b}$ & $75,00 \mathrm{~b}$ & $76,75 \mathrm{~b}$ & $50,00 \mathrm{~b}$ & $64,00 \mathrm{~b}$ & $75,50 \mathrm{~b}$ \\
\hline 2007 & $98,00 \mathrm{a}$ & $96,75 \mathrm{a}$ & $95,50 \mathrm{a}$ & $92,00 \mathrm{a}$ & $97,75 \mathrm{a}$ & $96,75 \mathrm{a}$ \\
\hline
\end{tabular}

*Médias seguidas de mesma letra, na coluna, não diferem entre si pelo teste F, a 5\% de significância.

Os resultados obtidos para a característica classificação do vigor das plântulas foram semelhantes aos observados no teste de germinação (Tabelas 1 e 3 ). Assim como para a porcentagem de germinação (Tabela 1), as épocas de semeadura 22/03 e 07/04 não permitiram as cultivares CD 110, CD 111 e CD 114, a obtenção de elevados índices de vigor, em 2006. Tais considerações também podem ser atribuídas à época $18 / 05$, a qual além de afetar a germinação, interferiu negativamente no vigor das plântulas. Isto indica que as condições climáticas evidenciadas nas épocas de semeadura antecipadas e mais tardias não favorecem a produção de sementes. Provavelmente, as condições ambientais ocorridas nas fases "críticas" da cultura, impediram a expressão do máximo potencial fisiológico destas cultivares. Os resultados encontrados no presente trabalho se assemelham aos obtidos por Tekrony et al. (1980), os quais constataram que a intensidade de redução da germinação e do vigor das plântulas varia de acordo com a época de semeadura e com as condições de temperatura, umidade relativa e precipitações pluviais durante as fases de maturação e colheita. 
TABELA 3. Resultados médios para os desdobramentos das interações entre cultivares, anos e épocas referentes à característica classificação do vigor das plântulas (\%), nas sementes provenientes de seis cultivares de trigo, em resposta a cinco épocas de semeadura em experimentos conduzidos no município de Palotina PR, nos anos 2006 e 2007.

\begin{tabular}{ccccccc}
\hline \multirow{2}{*}{$\begin{array}{c}\text { Épocas de } \\
\text { semeadura }\end{array}$} & \multicolumn{5}{c}{ Cultivares } \\
\cline { 2 - 7 } Ano 2006 & CD 104 & CD 105 & CD 108 & CD 110 & CD 111 & CD 114 \\
\hline $22 / 03$ & $82,50 \mathrm{aA} *$ & $81,25 \mathrm{aA}$ & $88,25 \mathrm{aA}$ & $60,25 \mathrm{bB}$ & $71,00 \mathrm{bB}$ & $61,25 \mathrm{bC}$ \\
$07 / 04$ & $78,50 \mathrm{aA}$ & $63,00 \mathrm{bB}$ & $80,50 \mathrm{aA}$ & $41,00 \mathrm{cC}$ & $43,50 \mathrm{cD}$ & $45,75 \mathrm{cD}$ \\
$20 / 04$ & $80,25 \mathrm{aA}$ & $88,75 \mathrm{aA}$ & $81,75 \mathrm{aA}$ & $75,25 \mathrm{aA}$ & $87,00 \mathrm{aA}$ & $88,50 \mathrm{aA}$ \\
$04 / 05$ & $57,00 \mathrm{bB}$ & $79,25 \mathrm{aA}$ & $75,50 \mathrm{aA}$ & $70,25 \mathrm{aA}$ & $78,25 \mathrm{aB}$ & $70,75 \mathrm{aB}$ \\
$18 / 05$ & $62,75 \mathrm{aB}$ & $71,25 \mathrm{aB}$ & $58,25 \mathrm{aB}$ & $36,75 \mathrm{bC}$ & $57,50 \mathrm{aC}$ & $59,25 \mathrm{aC}$ \\
\hline Ano 2007 & $\mathrm{CD} 104$ & $\mathrm{CD} 105$ & $\mathrm{CD} 108$ & $\mathrm{CD} 110$ & $\mathrm{CD} 111$ & $\mathrm{CD} 114$ \\
\hline $22 / 03$ & $91,50 \mathrm{aA}$ & $91,00 \mathrm{aA}$ & $83,00 \mathrm{aA}$ & $86,25 \mathrm{aA}$ & $89,75 \mathrm{aA}$ & $79,25 \mathrm{aB}$ \\
$07 / 04$ & $90,50 \mathrm{aA}$ & $93,75 \mathrm{aA}$ & $94,25 \mathrm{aA}$ & $90,75 \mathrm{aA}$ & $94,25 \mathrm{aA}$ & $79,00 \mathrm{bB}$ \\
$20 / 04$ & $76,25 \mathrm{bB}$ & $91,25 \mathrm{aA}$ & $86,50 \mathrm{aA}$ & $74,00 \mathrm{bB}$ & $79,00 \mathrm{bB}$ & $77,25 \mathrm{bB}$ \\
$04 / 05$ & $81,25 \mathrm{aB}$ & $89,00 \mathrm{aA}$ & $90,75 \mathrm{aA}$ & $90,75 \mathrm{aA}$ & $96,50 \mathrm{aA}$ & $92,25 \mathrm{aA}$ \\
$18 / 05$ & $95,50 \mathrm{aA}$ & $95,25 \mathrm{aA}$ & $91,75 \mathrm{aA}$ & $85,25 \mathrm{aA}$ & $93,50 \mathrm{aA}$ & $95,25 \mathrm{aA}$ \\
\hline
\end{tabular}

*Médias seguidas de pelo menos uma mesma letra, minúscula na linha, e maiúscula na coluna, pertencem ao mesmo agrupamento de acordo com ScottKnott (1974), em nível de 5\% de significância

No plantio realizado em 22/03, não houve diferenças significativas $(\mathrm{p}>0,05)$ entre os anos para as cultivares $C D$ 104, CD 105 e CD 108 (Tabela 4). Diferenças significativas $(p<0,05)$ foram observadas entre 2006 e 2007, para todas as cultivares, quando as semeaduras foram realizadas em 07/04 e 18/05. De maneira geral, no ano de 2007, foram obtidas maiores porcentagens de plântulas normais fortes, para todas as cultivares avaliadas, correspondendo também aos maiores percentuais de germinação (Tabela 2). Durante o período de maturação e colheita, as condições de ambiente foram favoráveis, isto é, não houve efeitos negativos da precipitação na qualidade fisiológica das sementes. Assim, as condições climáticas do ano de 2007 foram determinantes nas diferenças de resultados entre a qualidade das sementes produzidas nos dois anos.

Ao analisar a característica envelhecimento acelerado, pela Tabela 5, verifica-se que as sementes das cultivares CD 110, CD 111 e CD 114 (ano de 2006) foram menos vigorosas com relação às demais, nas épocas de semeadura de 22/03, 07/04 e 18/05. Resultados semelhantes foram obtidos nos testes de germinação e classificação do vigor das plântulas. Sugere-se que, a antecipação e o retardamento das épocas de semeadura possam ter interferido negativamente na capacidade das sementes "tolerarem" o estresse por temperatura e umidade relativa elevadas, ocasionado pelo teste de envelhecimento. Entre os fatores que interferem nas respostas, podem ser citadas as alterações metabólicas durante a germinação, incluindo metabolismo respiratório e funcionalidade das membranas (Basajavarajappa et al., 1991), a síntese de proteínas e metabolismo do DNA (Vásquez et al., 2001). Os resultados obtidos no presente trabalho discordam de Medina et al. e Sá et al. (1997), os quais verificaram que o atraso na época de semeadura propiciou uma melhoria de qualidade das sementes.

De acordo com Câmara (1991), a época de semeadura é definida por um conjunto de fatores ambientais que reagem entre si e interagem com a planta, promovendo variações nas características agronômicas e na qualidade das sementes. Dessa forma, o excesso de chuvas aliado à elevada umidade na ocasião da colheita, podem ter sido os fatores responsáveis pela redução da qualidade das sementes produzidas no ano de 2006. Além disso, os decréscimos da viabilidade e do vigor podem ser atribuídos às danificações nas membranas das mitocôndrias, promovendo redução da respiração aeróbica e da produção de ATP e acréscimos de etanol. Estes fatores são indicadores da intensidade da respiração e da disponibilidade de energia para o processo de germinação (Reedy e Knapp, 1990). 
TABELA 4. Resultados médios para o desdobramento da interação anos, cultivares e épocas referentes à característica classificação do vigor das plântulas (\%), nas sementes provenientes de seis cultivares de trigo, em resposta a cinco épocas de semeadura em experimentos conduzidos no município de Palotina - PR, nos anos 2006 e 2007.

\begin{tabular}{|c|c|c|c|c|c|c|}
\hline \multirow{4}{*}{ Anos } & \multicolumn{6}{|c|}{ Plântulas normais fortes (\%) } \\
\hline & \multicolumn{6}{|c|}{ Cultivares } \\
\hline & CD 104 & CD 105 & CD 108 & CD 110 & CD 111 & CD 114 \\
\hline & \multicolumn{6}{|c|}{ Épocas de Semeadura $(22 / 03)$} \\
\hline 2006 & $85,25 \mathrm{a}^{*}$ & $81,25 \mathrm{a}$ & 88,25 a & $60,25 \mathrm{~b}$ & $71,00 \mathrm{~b}$ & $61,25 \mathrm{~b}$ \\
\hline 2007 & 91,50 a & $91,00 \mathrm{a}$ & $83,00 \mathrm{a}$ & $86,25 \mathrm{a}$ & 89,75 a & $79,25 \mathrm{a}$ \\
\hline \multicolumn{7}{|c|}{ Épocas de Semeadura (07/04) } \\
\hline 2006 & $78,50 \mathrm{~b}$ & $63,00 \mathrm{~b}$ & $80,50 \mathrm{~b}$ & $41,00 \mathrm{~b}$ & $43,50 \mathrm{~b}$ & $45,75 \mathrm{~b}$ \\
\hline 2007 & $90,50 \mathrm{a}$ & $93,75 \mathrm{a}$ & $94,25 \mathrm{a}$ & $90,75 \mathrm{a}$ & $94,25 \mathrm{a}$ & $79,00 \mathrm{a}$ \\
\hline \multicolumn{7}{|c|}{ Épocas de Semeadura (20/04) } \\
\hline 2006 & $80,25 \mathrm{a}$ & 88,75 a & $81,75 \mathrm{a}$ & $75,25 \mathrm{a}$ & $87,00 \mathrm{a}$ & $88,50 \mathrm{a}$ \\
\hline 2007 & $76,25 \mathrm{a}$ & $91,25 \mathrm{a}$ & $86,50 \mathrm{a}$ & $74,00 \mathrm{a}$ & $79,00 \mathrm{a}$ & $77,25 \mathrm{~b}$ \\
\hline \multicolumn{7}{|c|}{ Épocas de Semeadura (04/05) } \\
\hline 2006 & $57,00 \mathrm{~b}$ & $79,25 \mathrm{a}$ & $75,50 \mathrm{~b}$ & $70,25 \mathrm{~b}$ & $78,25 \mathrm{~b}$ & $70,75 \mathrm{~b}$ \\
\hline 2007 & $81,25 \mathrm{a}$ & 89,00 a & $90,75 \mathrm{a}$ & $90,75 \mathrm{a}$ & $96,50 \mathrm{a}$ & $92,25 \mathrm{a}$ \\
\hline \multicolumn{7}{|c|}{ Épocas de Semeadura $(18 / 05)$} \\
\hline 2006 & $62,75 \mathrm{~b}$ & $71,25 \mathrm{~b}$ & $58,25 \mathrm{~b}$ & $36,75 \mathrm{~b}$ & $57,50 \mathrm{~b}$ & $59,25 \mathrm{~b}$ \\
\hline 2007 & $95,50 \mathrm{a}$ & $95,25 \mathrm{a}$ & $91,75 \mathrm{a}$ & $85,25 \mathrm{a}$ & 93,50 a & $95,25 \mathrm{a}$ \\
\hline
\end{tabular}

*Médias seguidas de mesma letra, na coluna, não diferem entre si pelo teste $\mathrm{F}$, a $5 \%$ de significância.

TABELA 5. Resultados médios para os desdobramentos das interações cultivares, anos e épocas referentes à característica envelhecimento acelerado (\%), nas sementes provenientes de seis cultivares de trigo, em resposta a cinco épocas de semeadura em experimentos conduzidos no município de Palotina - PR, nos anos 2006 e 2007.

\begin{tabular}{ccccccc}
\hline \multirow{2}{*}{$\begin{array}{c}\text { Épocas de } \\
\text { semeadura }\end{array}$} & \multicolumn{5}{c}{ Plântulas normais (\%) } \\
\cline { 2 - 7 } Ano 2006 & CD 104 & CD 105 & CD 108 & CD 110 & CD 111 & CD 114 \\
\hline $22 / 03$ & $92,50 \mathrm{aA} *$ & $83,50 \mathrm{aA}$ & $89,00 \mathrm{aA}$ & $60,50 \mathrm{bB}$ & $70,00 \mathrm{bB}$ & $55,50 \mathrm{bC}$ \\
$07 / 04$ & $74,50 \mathrm{aB}$ & $53,00 \mathrm{bB}$ & $80,50 \mathrm{aA}$ & $34,50 \mathrm{cC}$ & $50,00 \mathrm{bC}$ & $31,50 \mathrm{cD}$ \\
$20 / 04$ & $83,50 \mathrm{aA}$ & $91,00 \mathrm{aA}$ & $83,50 \mathrm{aA}$ & $91,50 \mathrm{aA}$ & $89,00 \mathrm{aA}$ & $88,50 \mathrm{aA}$ \\
$04 / 05$ & $68,50 \mathrm{bB}$ & $95,50 \mathrm{aA}$ & $93,00 \mathrm{aA}$ & $92,50 \mathrm{aA}$ & $96,00 \mathrm{aA}$ & $92,50 \mathrm{aA}$ \\
$18 / 05$ & $74,50 \mathrm{bB}$ & $82,00 \mathrm{aA}$ & $88,50 \mathrm{aA}$ & $48,00 \mathrm{cB}$ & $71,00 \mathrm{bB}$ & $71,50 \mathrm{bB}$ \\
\hline Ano 2007 & $\mathrm{CD} 104$ & $\mathrm{CD} 105$ & $\mathrm{CD} 108$ & $\mathrm{CD} 110$ & $\mathrm{CD} 111$ & $\mathrm{CD} 114$ \\
\hline $22 / 03$ & $86,00 \mathrm{aA}$ & $82,50 \mathrm{aA}$ & $74,00 \mathrm{aA}$ & $76,50 \mathrm{aA}$ & $80,00 \mathrm{aA}$ & $73,00 \mathrm{aA}$ \\
$07 / 04$ & $85,50 \mathrm{aA}$ & $90,00 \mathrm{aA}$ & $81,50 \mathrm{aA}$ & $85,50 \mathrm{aA}$ & $84,50 \mathrm{aA}$ & $73,00 \mathrm{aA}$ \\
$20 / 04$ & $76,50 \mathrm{aA}$ & $85,50 \mathrm{aA}$ & $57,00 \mathrm{bB}$ & $59,50 \mathrm{bB}$ & $67,50 \mathrm{bB}$ & $66,00 \mathrm{bA}$ \\
$04 / 05$ & $71,00 \mathrm{aA}$ & $62,50 \mathrm{aB}$ & $81,00 \mathrm{aA}$ & $66,00 \mathrm{aB}$ & $68,50 \mathrm{aB}$ & $74,50 \mathrm{aA}$ \\
$18 / 05$ & $83,50 \mathrm{aA}$ & $79,00 \mathrm{aA}$ & $68,00 \mathrm{aB}$ & $47,00 \mathrm{bC}$ & $73,00 \mathrm{aB}$ & $69,50 \mathrm{aA}$ \\
\hline
\end{tabular}

*Médias seguidas de pelo menos uma mesma letra, minúscula na linha, e maiúscula na coluna, pertencem ao mesmo agrupamento de acordo com ScottKnott (1974), em nível de 5\% de significância. 
Vale ressaltar ainda que, todas as cultivares apresentaram melhor desempenho quanto à porcentagem de germinação, após envelhecimento, na época de semeadura 20/04, no ano de 2006. Tal fato também pode ser verificado para as características porcentagem de germinação e classificação do vigor das plântulas. De maneira geral, no ano de 2007, notou-se que para todas as cultivares, as épocas 22/03 e 07/04 foram as melhores para o envelhecimento acelerado, bem como para as demais características avaliadas (Tabela 5). Um dos fatores que podem ter influenciado no comportamento diferenciado das cultivares nos dois anos, provavelmente seja devido à ocorrência de chuvas leves, em quantidades ideais, no período correspondente a semeadura, fato este que possibilitou a emergência uniforme das plântulas em campo. Esta afirmação concorda com Albuquerque e Carvalho (2003), os quais comentam que o efeito do vigor das sementes sobre o "vigor inicial das plântulas" depende das condições ambientais durante os estágios iniciais do desenvolvimento.

Braccini et al. (2003), observaram diferenças entre cultivares, em função do atraso na época de semeadura e do ano agrícola avaliado. No presente estudo, de modo geral, observou-se diferenças significativas $(p<0,05)$ entre os anos, para a maioria das épocas de semeadura e cultivares, quando avaliadas por meio dos testes de germinação e classificação do vigor das plântulas (Tabelas 2 e 4), sendo identificado o ano de 2007 como o mais promissor para a produção de sementes. Contudo, observa-se que, para algumas cultivares e épocas de semeadura, o ano de 2006 foi mais favorável em relação à porcentagem de germinação, após o período de envelhecimento das sementes (Tabela 6). Essas poucas diferenças entre os testes de vigor podem ser atribuídas ao princípio dos testes, ou seja, a porcentagem de geminação e a classificação do vigor das plântulas são considerados testes fisiológicos, que são baseados no desempenho das plântulas; enquanto o teste de envelhecimento acelerado avalia o desempenho das sementes expostas a estresse sob temperatura e umidade elevadas (Marcos Filho, 1999). Resultados discrepantes entre os testes de vigor foram relatados por Garcia et al. (2005), Ávila et al. (2005) e Coimbra e Nakagawa (2006).

TABELA 6. Resultados médios para o desdobramento da interação anos, cultivares e épocas referentes à característica envelhecimento acelerado (\%), nas sementes provenientes de seis cultivares de trigo, em resposta a cinco épocas de semeadura em experimentos conduzidos no município de Palotina - PR, nos anos 2006 e 2007.

\begin{tabular}{|c|c|c|c|c|c|c|}
\hline \multirow{4}{*}{ Anos } & \multicolumn{6}{|c|}{ Plântulas normais (\%) } \\
\hline & \multicolumn{6}{|c|}{ Cultivares } \\
\hline & CD 104 & CD 105 & CD 108 & CD 110 & CD 111 & CD 114 \\
\hline & \multicolumn{5}{|c|}{ Épocas de Semeadura $(22 / 03)$} & \\
\hline 2006 & $92,50 \mathrm{a}^{*}$ & $83,50 \mathrm{a}$ & $89,00 \mathrm{a}$ & $60,50 \mathrm{~b}$ & $70,00 \mathrm{a}$ & $55,50 \mathrm{~b}$ \\
\hline 2007 & $86,00 \mathrm{a}$ & $82,50 \mathrm{a}$ & $74,00 \mathrm{~b}$ & $76,50 \mathrm{a}$ & $80,00 \mathrm{a}$ & $73,00 \mathrm{a}$ \\
\hline \multicolumn{7}{|c|}{ Épocas de Semeadura $(07 / 04)$} \\
\hline 2006 & $74,50 \mathrm{a}$ & $53,00 \mathrm{~b}$ & $80,50 \mathrm{a}$ & $34,50 \mathrm{~b}$ & $50,00 \mathrm{~b}$ & $31,50 \mathrm{~b}$ \\
\hline 2007 & $85,50 \mathrm{a}$ & $90,00 \mathrm{a}$ & $81,50 \mathrm{a}$ & $85,50 \mathrm{a}$ & $84,50 \mathrm{a}$ & $73,00 \mathrm{a}$ \\
\hline \multicolumn{7}{|c|}{ Épocas de Semeadura $(20 / 04)$} \\
\hline 2006 & $83,50 \mathrm{a}$ & $91,00 \mathrm{a}$ & $83,50 \mathrm{a}$ & $91,50 \mathrm{a}$ & $89,00 \mathrm{a}$ & $88,50 \mathrm{a}$ \\
\hline 2007 & $76,50 \mathrm{a}$ & $85,50 \mathrm{a}$ & $57,00 \mathrm{~b}$ & $59,50 \mathrm{~b}$ & $67,50 \mathrm{~b}$ & $66,00 \mathrm{~b}$ \\
\hline \multicolumn{7}{|c|}{ Épocas de Semeadura $(04 / 05)$} \\
\hline 2006 & $68,50 \mathrm{a}$ & $95,50 \mathrm{a}$ & $93,00 \mathrm{a}$ & $92,50 \mathrm{a}$ & $96,00 \mathrm{a}$ & $92,50 \mathrm{a}$ \\
\hline 2007 & $71,00 \mathrm{a}$ & $62,50 \mathrm{~b}$ & $81,00 \mathrm{a}$ & $66,00 \mathrm{~b}$ & $68,50 \mathrm{~b}$ & $74,50 \mathrm{~b}$ \\
\hline \multicolumn{7}{|c|}{ Épocas de Semeadura $(18 / 05)$} \\
\hline 2006 & $74,50 \mathrm{a}$ & $82,00 \mathrm{a}$ & $88,50 \mathrm{a}$ & $48,00 \mathrm{a}$ & $71,00 \mathrm{a}$ & $71,50 \mathrm{a}$ \\
\hline 2007 & $83,50 \mathrm{a}$ & $79,00 \mathrm{a}$ & $68,00 \mathrm{~b}$ & $47,00 \mathrm{a}$ & $73,00 \mathrm{a}$ & $69,50 a$ \\
\hline
\end{tabular}

*Médias seguidas de mesma letra, na coluna, não diferem entre si pelo teste $\mathrm{F}$, a 5\% de significância. 
Vale salientar que, para todas as cultivares e épocas avaliadas quanto ao teor de água das sementes (\%), estas apresentaram umidade inicial variando entre 10,79 a $12,50 \%$ no ano de 2006, e, 10,84 a 11,77\% em 2007. Posteriormente a exposição ao envelhecimento, a umidade das sementes atingiu valores entre 19,98 a 29,62\% em 2006 e, 25,33 a $30,61 \%$, em 2007. Esses dados não foram analisados estatisticamente, servindo apenas para a caracterização inicial e monitoramento das cultivares após a realização do teste. Marcos Filho (1999) menciona que a variação mínima do teor de água das sementes é uma característica essencial para a padronização das avaliações e obtenção de resultados consistentes no teste de envelhecimento acelerado.

A partir dos resultados obtidos no presente trabalho, pode-se admitir que a qualidade das sementes das cultivares CD 105 e CD 108 foi menos influenciada pelas épocas de semeadura, nos dois anos de experimento. Foi possível constatar ainda que, a antecipação e o retardamento da época de semeadura prejudicaram o desempenho fisiológico das cultivares CD 110, CD 111 e CD 114. Além disso, podese afirmar que a data de semeadura mais indicada para a produção de sementes foi 20 de abril, no ano de 2006. Por outro lado, para 2007, as melhores épocas foram 22/03 e 07/04 para a obtenção de elevada qualidade de sementes.

\section{CONCLUSÕES}

$\mathrm{O}$ efeito do ano e das épocas de semeadura refletiu sobre a qualidade fisiológica de sementes, para a maioria das cultivares.

As maiores porcentagens de plântulas normais ocorreram no ano de 2007, para a maioria das cultivares, nas diferentes épocas de semeadura.

\section{REFERÊNCIAS}

ALBRECHT, L.P.; BRACCINI, A.L.; SCAPIM, C.A.; AGUIAR, C.G.; ÁVILA, M.R.; STULP, M. Qualidade fisiológica e sanitária das sementes sob semeadura antecipada da soja. Scientia Agraria, v.9, n.4, p.445-454, 2008.

ALBUQUERQUE, M.C. F.; CARVALHO, N.M. Effect of the type of environmental stress on the emergence of sunflower (Heliantus annus L.), soybean (Glycine max L.) and maize (Zea mays L.) seeds with different levels of vigor. Seed Science and Technology, v.31, n.2, p.465-479, 2003.

ÁVILA, M.R.; BRACCINI, A.L.; SCAPIM, C.A.; MARTORELLI, D.T.; ALBRECHT, L.P. Testes de laboratório em sementes de canola e a correlação com a emergência das plântulas em campo. Revista Brasileira de Sementes, v.27, n.1, p.62-70, 2005.

BANZATTO, D.A.; KRONKA, S.N. Experimentação agrícola. Jaboticabal: FUNEP, 1989. 247p.

BASAJAVARAJAPPA, B.S.; SHETY, H.S.; PRAKASH, H.S. Membrane deterioration and other biochemical changes, associated with accelerated aging of maize seeds. Seed Science and Technology, v.2, n.2, p.279-286, 1991.

BRACCINI, A.L.; MOTTA, I.S.; SCAPIM, C.A.; BRACCINI, M.C.L.; ÁVILA, M.R.; SCHUAB, S.R.P. Semeadura da soja no período de safrinha: potencial fisiológico e sanidade das sementes. Revista Brasileira de Sementes, v.25, n.1, p.76-86, 2003.

BRASIL. Ministério da Agricultura e Reforma Agrária. Secretaria Nacional de Defesa Agropecuária. Departamento Nacional de Defesa Vegetal. Coordenação de Laboratório Vegetal. Regras para análise de sementes. Brasília, DF, 1992. 365p.

CÂMARA, G.M.S. Efeito do fotoperíodo e da temperatura no crescimento, florescimento e maturação de cultivares de soja (Glycine $\max$ (L.) Merrill). 1991. 266f. Tese (Doutorado) - Universidade Federal de Viçosa, Viçosa, 1991.

CARVALHO, N.M; NAKAGAWA, J. Sementes: ciência, tecnologia e produção. 4.ed., Jaboticabal: FUNEP, 2000. 588 p.

CASTRO, R.D.; BRADFORD, K.J.; HILHORST, H.W.M. Desenvolvimento de sementes e conteúdo de água. In: FERREIRA, A.G.; BORGHETTI, F (Coord). Germinação: do básico ao aplicado. Porto Alegre: Artmed, 2004. 323p.

COIMBRA, R.A.; NAKAGAWA, J. Época de semeadura, produção e qualidade fisiológica de sementes de milheto. Revista Brasileira de Sementes, v.28, n.2, p.53-59, 2006.

CRUZ, C.D.; REGAZZI, A.J.; CARNEIRO, P.C.S. Modelos biométricos aplicados ao melhoramento genético. 3.ed. Viçosa: UFV, 2004. v.1. 480p.

EGLI, D.B; TEKRONY, D.M. Relationship between soybean seed vigour and yield. Agronomy Journal, v.17, n.2, p.755-759, 1979.

FANAN, S.; MEDINA, P.F.; LIMA, T.C.; MARCOS- 
FILHO, J. Avaliação do vigor de sementes de trigo pelos testes de envelhecimento acelerado e de frio. Revista Brasileira de Sementes, v.28, n.2, p.152-158, 2006.

FERREIRA, D.F. SISVAR 4.3 - Sistema de análises estatísticas. Lavras: UFLA, 1999.

GARCIA, D.C.; BARROS, A.C.S.A.; PESKE, S.T.; MENEZES, N.L. Qualidade fisiológica e sementes de trigo submetidas à secagem estacionária com ar ambiente forçado.

Revista Brasileira de Sementes, v.28, n.1, p.106-113, 2005.

GODOY, H.; BERNARDES, L.R.M. Clima e trigo no Paraná. In: MOTA, F.S. Agrometeorologia do trigo no Brasil. Campinas, Sociedade Brasileira de Agrometeorologia. 1989. p.36-56.

HAMPTON, J.G.; COOLBEAR, P. Potential versus actual seed performance: can vigor testing provide an answer? Seed Science and Tecnology, v.18, n.1, p.215-218, 1990.

IAPAR. Fundação Instituto Agronômico do Paraná. Informações técnicas para a cultura do trigo no Paraná, 2002. Londrina, 2002. 180p. (IAPAR. Circular, 122).

LIMA, T.C.; MEDINA, P.F.; FANAN, S. Avaliação do vigor de sementes de trigo pelo teste de envelhecimento acelerado.

Revista Brasileira de Sementes, v.28, n.1, p.106-113, 2006.

LINHARES, A.G.; NEDEL, J.L. Clima e germinação do trigo na espiga. In: MOTA, F.S. Agrometeorologia do trigo no Brasil. Campinas: Sociedade Brasileira de Agrometeorologia. 1989. p.95-101.

LOMAS, S.J. Meteorological requirements of the wheat crop. In: WMO SYMPOSIUM AGROMETEOROLOGY OF THE WHEAT CROP, 1976, Braunschweig, Federal Republic of Germany. Symposium... Braunschweig, 1976 (WMO 396).

MAIA, A.R.; LOPES, J.C.; TEIXEIRA, C.O. Efeito do envelhecimento acelerado na avaliação da qualidade fisiológica de sementes de trigo. Ciência e Agrotecnologia, v.31, n.3, p.678-684, 2007.

MANFRON, P.A.; LAZZAROTTO, C.; MEDEIROS, S.L.P. Trigo - aspectos agrometeorológicos. Ciência Rural, v.23, n.2, p.233-239, 1993.

MAPA. Ministério da Agricultura, Pecuária e Abastecimento.
Instrução Normativa $\mathrm{N}^{\circ} 25$, de 16 de dezembro de 2005. Anexo XII - Padrões para produção e comercialização de sementes de trigo e de trigo duro. Disponível em: $<$ http://extranet.agricultura.gov.br/sislegis-consulta/servlet/ VisualizarAnexo?id=10813>. Acesso em: 28 jan. 2009.

MARCOS FILHO, J. Teste de envelhecimento acelerado. In: KRZYZANOWSKI, F.C.; VIEIRA, R.D.; FRANÇANETO, J.B. (Ed.). Vigor de sementes: conceitos e testes. Londrina: ABRATES, 1999. cap.3.1 - p.3.24.

MARCOS FILHO, J. Testes de vigor: importância e utilização. In: KRZYZANOWSKI, F.C.; VIEIRA, R.D.; FRANÇA-NETO, J.B. (Ed.). Vigor de sementes: conceitos e testes. Londrina: ABRATES, 1999. cap.1.1 - p.1.21.

MEDINA, P.F.; RAZERA, L.F.; MARCOS FILHO, J.; BORTOLETTO, N. Produção de sementes de cultivares precoces de soja em duas épocas e dois locais paulistas: II. Qualidade fisiológica, Bragantia, v. 56, n.2, p.305-315, 1997.

MÓS, M. Changes in the germinability and vigour of winter triticale seeds with sprouting damage. Plant Soil Environmental, v.49, n.3, p.126-130, 2003.

MOTA, F.S. Clima, tecnologia e produtividade do trigo no Brasil. In: MOTA, F.S. Agrometeorologia do trigo no Brasil. Campinas: Sociedade Brasileira de Agrometeorologia, 1989. p.1-35.

MOTTA, I.S.; BRACCINI, A.L.; SCAPIM, C.A. INOUE, M.H.; ÁVILA, M.R.; BRACCINI, M.C.L. Época de semeadura em cinco cultivares de soja. II. Efeito na qualidade fisiológica das sementes. Acta Scientiarum, v.24, n.5, p.1281-1286, 2002.

NAKAGAWA, J. Testes de vigor baseados no desempenho das plântulas. In: KRZYZANOWSKI, F.C.; VIEIRA, R.D.; FRANÇA-NETO, J.B. Vigor de sementes: conceitos e testes. Londrina: ABRATES, 1999. cap. 2.1 - p.2-24.

PEREIRA,E.B.C.;PEREIRA,A.V.;FRAGA,A.C.Qualidade de sementes de cultivares precoces de soja produzidas em três épocas. Pesquisa Agropecuária Brasileira, v.35, n.8, p.1653-1662, 2000.

REEDY, M.E.; KNAPP, A.D. Ethanol evolution during the early germination of artificially aged soybean seeds. Journal of Seed Technology. v.14, n.2, p.74-82, 1990.

SÁ, M.E.; ARF, O.; RODRIGUES, R.A.F.; OLIVEIRA, 
G.S. Efeitos de épocas de semeadura sobre a produção e qualidade fisiológica de sementes de nove cultivares de arroz irrigado por aspersão. Revista Brasileira de Sementes, v.19, n.2, p.244-253, 1997.

SCHEEREN, P.L.; CUNHA, G.R.; QUADROS, F.J.S.; MARTINS, L.F. Efeito do frio em trigo. Passo Fundo: Embrapa Trigo, 2000. 2p. (Embrapa Trigo. Comunicado Técnico Online, 57). Disponível em: <http://www.cnpt. embrapa.br/biblio/p_co57.htm>. Acesso em: 20 jan. 2009.

SCOTT, A.; KNOTT, M. Cluster-analysis method for grouping means in analysis of variance. Biometrics, v.30, n.3, p.507-512, 1974.

SILVA, A.R. da. Trigo no sul de Mato Grosso. Campo Grande: IPEAO, 1971. 24p.

SILVA, J.B.; LAZARINI, E.; SÁ, M.E. Avaliação de genótipos de soja em semeadura de inverno, em Selvíria, MS: produção e qualidade fisiológica de sementes. Revista Brasileira de Sementes, v. 29, n.3, p.189-196, 2007.

SMANHOTTO, A.; NÓBREGA, L.H.P.; OPAZO, M.A.U.;
PRIOR, M. Características físicas e fisiológicas na qualidade industrial de cultivares e linhagens de trigo e triticale. Revista Brasileira de Engenharia Agrícola e Ambiental, v.10, n.4, p.867-872, 2006.

SOLTANI, E.; GALESHI, S.; KAMKAR, B.; AKRAMGHADERI, F. The effect of seed aging on the seedling growth as affected by environmental factors in wheat. Research Journal of Environmental Sciences, v.3, n.2, p.184-192, 2009.

TEKRONY, D.M.; EGLY, D.B.; PHILLIPS, A.D. Effects of field weathering on the viability and on vigor of soybean seed. Agronomy Journal, v.72, n.5, p.749-753, 1980.

TOLEDO, M.Z.; COIMBRA, R.A.; NAKAGAWA, J. Qualidade fisiológica e armazenamento de sementes de milheto em função da época de semeadura. Bioscience Journal, v.25, n.3, p.16-23, 2009.

VÁSQUEZ, E.; MONTIEL, F.; VÁSQUEZ-RAMOS, J.M. DNA ligase activity in deteriorated maize axes during germination: a model relating defects in DNA metabolism in seeds to loss of germinability. Seed Science Research, v.1, n.2, p.269-273, 1991. 